\title{
A descriptive study to assess the knowledge and practice of health hazards of junk food consumption among adolescent in selected urban school, haldwani, Uttarakhand.
}

\author{
Mrs. Thamarai Selvi.M', Ms. Binita Papola ${ }^{2}$, Ms. Dharshani Rawat ${ }^{3}$, \\ Ms. Deepa Joshi ${ }^{4}$, Ms. Deepika Kharayat ${ }^{5}$. \\ ${ }^{1 .}$ PhD Scholar, Vice Principal, Naincy College of Nursing, Uttrakhand. \\ ${ }^{2,3,4, \& 5 .}$ B.Sc nursing, IV year, Naincy College of Nursing, Uttrakhand. \\ Corresponding Email : pthamus@gmail.com:
}

\begin{abstract}
INTRODUCTION: Junk food includes those food items that do not add any value to a person's diet. Here value denotes essential nutrients, vitamins and minerals. A study was conducted to assess the knowledge and practice of health hazards of junk food among adolescents in selected urban school.

MATERIALS \& METHODS: The sample of this study comprise of 60 students were selected by Simple random sampling methods. Data collected by structured questionnaire and analyzed by using descriptive and inferential statistics.

Results: Data collected by structured questionnaire and analyzed by using descriptive and inferential statistics with mean percentage was $70 \%$ and mean for practice mean percentage was $58 \%$. The data analysis revealed that there is non- significant association between knowledge and age, sex, residential status, religion, income of family, economical status, father's education, mother's education, father's occupation, mother's occupation. And there is significant association between practice and age, religion, Mother's occupation.

Conclusion: The study revealed that there is practice regarding health hazards of junk food is higher than the knowledge regarding consumption of food.
\end{abstract}

Keywords: Knowledge, Practice, Junk food.

\section{Introduction:}

Junk food is a term describing food that is perceived to be unhealthy or having poor nutritional value, according to Food Standards Agency. Junk food includes those food items that do not add any value to a person's diet. Here value denotes essential nutrients, vitamins and minerals. Poor nutrition adolescent periods can have lasting consequences on a adolescent's Cognitive development, resulting in decreased learning ability, poor concentration and impaired school performance eating junk food has become a trend. The children hate homemade healthy food. ${ }^{1}$

According to WHO report 40,000 deaths occur per year in world due to excessive intake of junk food. It has been found that India's over weight rates increased by $20 \%$. Now India is in the grip of an obesity epidemic. Experts says that trends needs to be immediately arrested by restricting food advertisements and making food labelling center. Worlds adolescent population is 1200 million persons in 10-19 years of age , or about $19 \%$ of the total population faces a series of serious nutritional challenges. ${ }^{2}$

Junk food are typically ready to eat convenience foods containing high levels of saturated fats, salt or sugar and little or no fruit, vegetables or dietary fiber and are considered to have little or no health benefits. Common junk food includes salted snack foods like chips (crsps), candy, gum, most sweet desserts, fried 
fast food and carbonated beverages (sodas) as well as alcoholic beverages. The food habitats in India have changed due to the western influence and the usage of foods is also on the rise and have been a part of everyday life. ${ }^{3}$

\section{Need for the study:}

In India, the consumer spending rate on processed food had increased at an average rate of $7.6 \%$ annually during the years 2008 to 2010 and this was expected to continue as the consumer expense would rise with an average of around $8.6 \%$ till the year 2012 . 30\% of children aged 2-19 years are considered overweight or obese and has been estimated that 1 in 3 children born in the year 2000 will develop diabetes in their lifetime over the past 3 decades the childhood obesity rate has more doubled for pre-school children aged 2-5 years and adolescents aged 12-19 years and it has more tripled for children aged 6-11 years. ${ }^{4}$

A survey was conducted by Association of chambers of commerce and industries in 25 private and public school canteens in five major cities - Ahmedabad, Mumbai, Kolkata, Chennai including Chandigarh, among 5000 high school students. The survey disclosed that $53 \%$ of children in Chandigarh spend an average of Rs. 700 to 1000 every month on junk food in school canteens. Another alarming finding was that $59 \%$ of the food served in canteens was junk food. It revealed that kids prefer to snack on junk food which is heavy in fats, salt and sugar and warns that if the trend continues, the kids are set to develop lifestyle diseases. ${ }^{5}$

\section{Problem Statement}

A descriptive study to assess the knowledge and practice of health hazards of junk food consumption among adolescent in selected urban school, haldwani, Uttarakhand.

\section{Objectives of the problem}

1. To assess the knowledge and practice of adolescents regarding the health hazards of junk food in selected urban area.

2. To find the association between knowledge and practice of adolescents with their selected demographic variables.

3. To find out the correlation between knowledge practice regarding consumption of junk food.

\section{Materials and methods:}

The investigator has selected exploratory research design to assess the knowledge and practice of adolescent among urban school children. The setting of the study is in urban school, Uttarakhand. The accessible population of present study includes urban school adolescents in selected schools, Uttarakhand. The sample of the present study comprised of 50 adolescents of urban school. Simple random sampling was found appropriate for the study. In the present study the tool consist of two parts:

Part 1: consist of socio-demographic variable.

Part 2: Comprise of questionnaire regarding consumption of junk food.

The investigator had collected the data after getting formal permission from the authority from the selected urban schools, Uttarakhand and approval was obtained to conduct the study. The participants were informed about the purpose of the study and written consent was taken from the participants. On an average each participants took 30 minutes to complete the questionnaire/tool. The investigator did not face any significant problem and the tool was found reliable.

Table 1: Overall Mean Value For Knowledge And Practice Of Health Hazards Of Junk Food Consumption

\begin{tabular}{|l|l|l|}
\hline Mean & Knowledge & Practice \\
\hline & 0.699 & 0.57 \\
\hline
\end{tabular}

Table 1: reveals that mean value for the knowledge is 0.699 and for practice 0.57 .

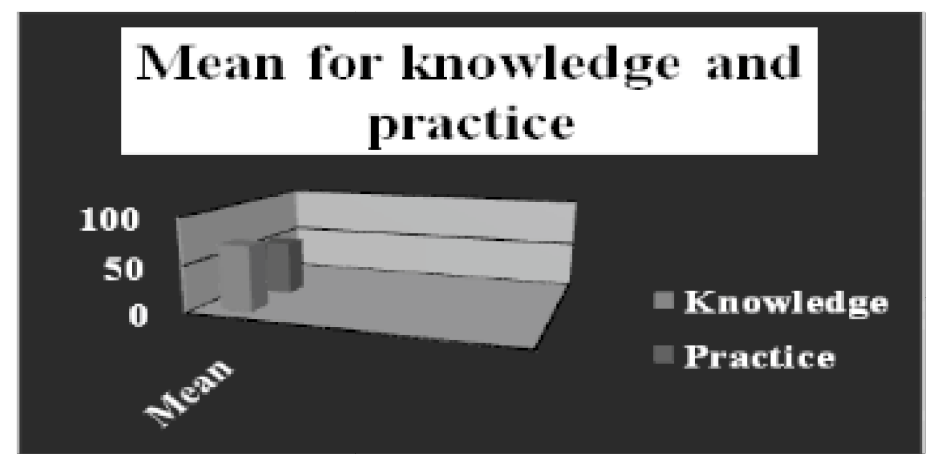

Figure 1: Shows overall mean value for knowledge and practice of health hazards of junk food consumption among adolescents. 
Table 2: Relationship between knowledge and practice of health hazards of junk food consumption.

$\mathbf{N}=60$

\begin{tabular}{|l|l|l|c|l|}
\hline Variable I & Variable II & Correlation by & R & Inference \\
\hline Knowledge & Practice & Karl Pearson & 1 & $\begin{array}{l}\text { Perfect positive } \\
\text { Correlation }\end{array}$ \\
\hline
\end{tabular}

Analysis revealed that there is a correlation between knowledge practice regarding health hazards of junk food consumption and the $r$ value is : 1 , It indicates perfect positive correlation.

\section{Discussion:}

1. To assess the knowledge and practice of adolescents regarding the health hazards of junk food in selected urban area.

The finding of this study reveals that the Mean percentage for knowledge is $70 \%$, and SD is 14.87 and for practice Mean percentage is (58\%) and SD is 20.55. The researcher concludes that adolescents have more knowledge than the practice.

2. To find the association between knowledge and practice of adolescents with their selected demographic variables.

Association between knowledge and practice score with selected demographic variables was done by using chi-square. The data analysis revealed that there is non- significant association between knowledge and age, sex, residential status, religion, income of family, economical status, father's education, mother's education, father's occupation, mother's occupation. And there is significant association between practice and age, religion, Mother's occupation.

\section{To find out the correlation between knowledge practice regarding consumption of junk food.}

Analysis revealed that there is a correlation between knowledge and practice regarding health hazards of junk food consumption and the r value is: 1 , It indicates perfect positive correlation.

\section{Recommendations:}

The study can be replicated in large samples for better generalization Conclusion: The researcher concludes that knowledge can improve the healthy practices among adolescents also low nutrient foods are ubiquitous and efforts should be made to reduce their availability in multiple settings.

Acknowledgement: Editor-in-chief (IJSN) \& (IJNAE): Dr.Pramilaa.R

\section{REFERENCES:}

1. http://medical dictionary. The free dictionary. com. adolescence.

2. Ask Encyclopedia. Available from http://wiki.ask.com/food

3. Sharma V. Adolescent's knowledge regarding harmful effects of junk food. ISOR journal of nursing and health sciences 2013; (6): 1-4.

4. Bayol SA,Macharia R, Farrington SJ,Simbi BH, Stickland NC, Evidence that a maternal. junk food. diet during pregnancy and lactation can reduce muscle force in off spring. Eur J Nutr 2009;48:62-5.

5. 7-Steep rise in fast food consumption in Indiaavailable from: http://www.fnbnews.com/article/detnews.9.asp? Articleid-29019. 